\title{
Entre o ideal e o real: percepções e práticas acerca da divisão de atividades domésticas e de cuidados no Brasil
}

\author{
Andréa Branco Simão*
}

\author{
ARAÚJO, C.; GAMA, A.; PICANÇO, F.; CANO; I. (org.). Gênero, \\ família e trabalho no Brasil do século XXI: mudanças e \\ permanências. Rio de Janeiro: Gramma, 2018.
}

Tentar conciliar as diversas demandas que emergem na vida cotidiana é um exercício diário e um dilema ainda longe de ser resolvido, que aflige grande parte das mães trabaIhadoras. 0 livro Gênero, família e trabalho no Brasil do século XXI - mudanças e permanências, lançado em 2018 pela Gramma Editora, joga luz nessa discussão ao analisar as implicações que o entrelaçamento entre gênero, família e trabalho tem, ainda hoje, para o estabelecimento de relações mais igualitárias entre homens e mulheres no país.

Organizado por Clara Araújo, Andréa Gama, Felícia Picanço e Ignácio Cano, o livro descreve resultados do projeto "Gênero, trabalho e família no Brasil - mudanças e permanências nas últimas décadas”, reunindo sete artigos que apresentam, a partir de uma perspectiva de gênero, percepções e práticas relativas à divisão de atividades domésticas e de cuidados com filhos pequenos. Os dados empregados em todos os estudos são provenientes de dois surveys que possuem uma amostra representativa da população brasileira de 18 anos e mais, realizados em 2003 e 2016-2017. As perguntas utilizadas foram adaptadas do questionário elaborado pelo International Social Survey Programme de 2012 (módulo IV). No total, 1.575 indivíduos, entre homens e mulheres, foram entrevistados. Escolaridade, conjugalidade, raça/cor, religião e emprego doméstico foram variáveis enfatizadas pelos autores e autoras que colaboraram em cada um dos diferentes capítulos que compõem a coletânea.

\footnotetext{
*Universidade Federal de Minas Gerais (UFMG - Cedeplar) e Pontifícia Universidade Católica de Minas Gerais (PUC-Minas), Belo Horizonte-MG, Brasil (deia@cedeplar.ufmg.br; https://orcid.org/0000-0003-2514-0301).
} 
O texto de abertura, de Clara Araújo, Felícia Picanço, Ignácio Cano e Alinne Veiga, único da coletânea a comparar os resultados do survey de 2003 com os de 2016-2017, mostra que, embora ao longo desses anos tenham acontecido algumas mudanças em definições de papéis de gênero e em atitudes e práticas relativas à divisão do trabalho doméstico, as mulheres ainda continuam assumindo grande parte das atividades em casa. São elas, também, que se dedicam mais aos cuidados com pessoas dependentes da família, particularmente com filhos pequenos. Já os homens, apesar de terem apresentado um maior envolvimento com as atividades de casa e de cuidados com os filhos, ainda não se dedicam tanto quanto as mulheres a essas tarefas. Isso não impede, contudo, que a percepção masculina de participação tenha aumentado de um período para o outro. De maneira geral, os resultados desse estudo reafirmam alguns fatos que já se conhecem - por exemplo, nas últimas décadas houve redução no número de filhos tidos por mulher, ampliação do nível de escolaridade dos indivíduos (com vantagem para as mulheres), redução das pessoas sem renda, declínio no número de pessoas vivendo com alguém e aumento dos domicílios unipessoais e daqueles formados por duas a quatro pessoas. Ocorreu, também, crescimento dos domicílios que contam com ajuda de uma empregada doméstica, mas, surpreendentemente, estes não são os domicílios de famílias com filhos. Os resultados também mostram que, apesar da redução nos percentuais de conjugalidade, a maior parte das pessoas ainda vive conjugalmente e tem filhos. Observou-se, ainda, decréscimo no percentual de homens que não se dedicam a nenhuma tarefa doméstica, mas a escolaridade não tem impacto nesse aspecto, a não ser entre as mulheres, que possuem uma carga de atividade doméstica mais elevada quando têm filhos. Em 2016-2017, embora tenha sido constatado aumento no envolvimento do homem com filhos em atividades domésticas, isso não foi suficiente para gerar uma redução no gap do número de horas dedicadas, por homens e mulheres, às atividades domésticas. Surpreendentemente, quando se trata da divisão das tarefas, os resultados mostram uma postura mais tradicional de indivíduos que trabalham mais de 40 horas e daqueles com nível superior.

O estudo de Andréa Gama, Bila Sorj, Karolyne Romero e Alinne Veiga vem na sequência e analisa as percepções, de homens e mulheres trabalhadores, sobre a divisão de gênero apropriada para a vida familiar e para a atividade remunerada e também sobre as práticas relativas ao trabalho doméstico e ao cuidado. Considerando as respostas de homens e mulheres, as autoras apontam que, se, por um lado, a participação no mercado de trabalho favorece a adesão a valores de gênero mais igualitários (particularmente entre mulheres com melhores rendimentos), por outro, as práticas de divisão de responsabilidade doméstica e de cuidado das crianças do domicílio permanecem na direção do modelo tradicional. 0 aumento do envolvimento masculino nas atividades domésticas acontece, com maior evidência, em trabalhos ligados a pequenos concertos, a lavar louça e a fazer compras no supermercado. De acordo com os resultados, eles também acreditam que brincam mais com os filhos e que estão mais envolvidos em atividades concernentes ao acompanhamento escolar. Essa crença, contudo, não é compartilhada pelas mulheres trabalhadoras, que, 
no final das contas, continuam mais envolvidas com os trabalhos rotineiros e de cuidados, diferentemente dos homens, que se comprometem mais com atividades de lazer que favorecem a interação com os filhos.

0 terceiro artigo, de Moema Guedes, se propõe a pensar as articulações entre escolaridade e percepções e valores mais igualitários no contexto das relações de gênero, reforçando a importância do papel da educação formal para evidenciar as desigualdades entre homens e mulheres. Segundo a autora, embora pessoas mais escolarizadas tendam a perceber com mais clareza as lacunas que ainda existem entre homens e mulheres, os homens, mesmo quando apresentam níveis mais elevados de educação, revelam maiores dificuldades para saírem do seu espaço de conforto e assumirem, de fato, atitudes mais igualitárias. A autora chama a atenção para o papel que a ampliação do ensino superior e a religião podem exercer nas percepções e práticas das pessoas no âmbito das relações de gênero e questiona se a escolaridade, como já mostrado em estudos anteriores, ainda desempenha um papel central na construção de relações de gênero mais igualitárias. Para tratar desse dilema, ela analisa algumas questões relacionadas às percepções apresentadas acerca das licenças maternidade e paternidade. Seus resultados apontam que trabalhar fora e ter um nível de escolaridade mais elevado gera respostas positivas, no que tange não somente à percepção da importância das licenças maternidade e paternidade, mas também à ampliação do período concedido para tais licenças, tanto para a mãe quanto para o pai, para que ambos possam permanecer mais tempo com a criança e compartilhar os cuidados devidos ao bebê no início da vida. Apesar disso, a licença paternidade, como ressalta a autora, é limitada a poucos dias, indicando que as tarefas de cuidado com o filho ainda parecem ser consideradas de responsabilidade da mãe e que, ao pai, cabe o papel de provedor. As licenças maternidade e paternidade ainda são pontos polêmicos no Brasil e demandam um debate mais profundo sobre como viabilizar uma divisão mais igualitária das atividades implicadas nos cuidados com os filhos desde o início da vida das crianças, mesmo sendo a mulher a única a poder amamentar.

A seguir, Maira Covre-Sussai, Jadir Soares e Thaiana Rodrigues analisam valores e atitudes relativos à divisão do trabalho e ao cuidado de homens e mulheres vivendo diferentes tipos de arranjos conjugais e contextos sociais. Os resultados revelam que mulheres, pessoas solteiras e separadas e pessoas vivendo nas regiões Sul e Sudeste se mostram menos conservadoras do que aquelas casadas ou em união, vivendo nas regiões Norte e Centro-Oeste do país. Além disso, os resultados indicam que, no quesito organização familiar e de cuidado, as pessoas mais jovens e as mais escolarizadas são menos conservadoras do que aquelas mais velhas e com menores níveis de escolaridade. Infelizmente, os resultados também mostram que, quando se trata da divisão das tarefas domésticas, as pessoas mais jovens e mais escolarizadas se mostram mais conservadoras. Esse é um aspecto que merece ser investigado mais a fundo. Supostamente, pessoas mais jovens e com maiores níveis de escolaridade deveriam estar mais próximas de perspectivas mais igualitárias. 0 velho modelo de concentração das atividades domésticas na figura da mulher parece ter raízes 
mais profundas do que se esperava - ou, pelo menos, que algumas pessoas esperavam. Inevitável, contudo, não pensar sobre as possíveis relações que esse comportamento exibido pelos jovens e pelos mais escolarizados pode ter com a questão de classe. Como mostrou Itaboraí (2017), há uma variação na carga de trabalho doméstico e de cuidado por classe. Filhos das classes mais baixas se tornam independentes e assumem diversas responsabilidades muito mais cedo do que os filhos de classes mais altas.

No quinto artigo, José Eustáquio Diniz Alves e Angelita Carvalho dão continuidade às análises, incluindo a variável raça/cor ao estudo. Os autores argumentam que, embora a sociedade esteja seguindo em uma direção mais igualitária, as análises acerca das percepções sobre papéis no mercado de trabalho, na sociedade e na família, segundo raça/cor, não podem ser consideradas unânimes. Enquanto os brancos possuem uma postura mais igualitária acerca do que seria uma família ideal para a criação dos filhos, concordando mais com o fato de que uma mãe ou um pai sozinho pode criar o filho tão bem quanto um casal, os pretos e os pardos têm uma visão mais igualitária sobre o papel desempenhado por homens e mulheres, em especial no que diz respeito ao menor prejuízo do trabalho feminino sobre a criação dos filhos. Os contextos sociais e regionais em que os indivíduos vivem, de acordo com os autores, são fundamentais para a construção de valores e percepções. Diante dos resultados encontrados, é importante pensar no longo processo de marginalização vivenciado pelos negros no Brasil e como isso pode ter afetado suas percepções e práticas em relação à participação feminina no mercado de trabalho. 0 trabalho, em suas diferentes formas, sempre fez parte da realidade de mulheres negras, para as quais as possibilidades de acesso a maiores níveis de escolaridade, a profissões de maior prestígio e a melhores salários, por exemplo, sempre foram menores. Como pontua Hasenbalg (2005), os efeitos de práticas discriminatórias sutis e de mecanismos racistas mais gerais, existentes no país, fazem com que os pretos e pardos tenham oportunidades educacionais mais limitadas do que os brancos de mesma origem social. As realizações educacionais de pretos e pardos se expressam, consequentemente, em ganhos ocupacionais e de renda menores do que os apresentados pelos brancos. Assim, apesar da falta de unanimidade nos resultados segundo raça/cor, não se podem desconsiderar as desvantagens enfrentadas por pretos e pardos em diferentes esferas dos espaços público e privado.

0 papel das afiliações religiosas na divisão das tarefas domésticas é investigado por Doriam Borges, que pontua a existência do cenário de diversidade religiosa brasileiro. Considerando tal aspecto, Borges argumenta que a religião, para fins da análise que desenvolve, deve ser entendida como ensinamentos, valores, costumes, tradições, culturas e práticas, exercendo um efeito sobre como as pessoas percebem a sociedade. Por essa razão, a religião pode interferir na forma como as atividades domésticas e os cuidados com os filhos são organizados. A análise é desenvolvida considerando pessoas praticantes, não praticantes e que apenas creem em Deus, mas declaram não ter uma afiliação religiosa. Uma das conclusões centrais é de que os valores religiosos influenciam a igualdade de gênero. Em geral, os evangélicos pentecostais praticantes são mais conservadores em relação ao 
papel da mulher na família e apresentam maiores diferenças, por sexo, nas práticas de cuidados com os filhos. Apesar disso, o autor ressalta em seus resultados que a geração de renda tem um papel importante para esse grupo, o que significa que a inserção da mulher no mercado de trabalho remunerado, por necessidade financeira, não é vista como um dano potencial para ela e nem para a família. Já os evangélicos não pentecostais praticantes são mais conservadores em relação ao trabalho da mãe no mercado remunerado. A mulher é vista como mãe e cuidadora do lar. Os resultados do estudo também indicam que as mulheres que frequentam igrejas evangélicas não pentecostais apresentam uma visão mais conservadora em relação ao papel da mulher e da família. Entre os casais católicos, o cuidado com a casa se concentra nas mulheres, as quais ficam mais sobrecarregadas do que os homens, que se dedicam a atividades voltadas para consertos esporádicos. As pessoas sem religião, mas que acreditam em Deus, são mais conservadoras em relação ao papel da mulher na família, enquanto os indivíduos menos conservadores em relação ao papel da mulher na família são aqueles afiliados a religiões de matriz africana. Os homens kadercistas, por sua vez, desenvolvem mais atividades domésticas do que as mulheres, que, quando afiliadas a essa doutrina, são, em geral, mais conservadoras do que os homens.

0 texto de Ângela Sartor, Mariana Siracusa e Paula Neves fecha o volume discutindo como, na prática, o papel do emprego doméstico pode servir de mediador das percepções de gênero no cotidiano da vida familiar e de trabalho remunerado das pessoas. As autoras ressaltam que o emprego doméstico é a terceira maior ocupação feminina no país, mas o número de domicílios que contam com a participação de uma empregada doméstica ou de uma diarista é pequeno - em torno de $15 \%$ entre os respondentes da pesquisa -, indicando que a delegação do trabalho doméstico (uma atividade ainda pouco valorizada), para outras mulheres, não somente é restrita a uma determinada camada da população, como também não colabora para a diminuição das assimetrias de gênero. De acordo com as pesquisadoras, a delegação das atividades para uma outra mulher modifica a forma como ocorre a divisão das atividades domésticas na família e a percepção da dinâmica envolvida na conciliação entre trabalho e família muito mais entre os homens do que entre as mulheres. Para os homens brancos, de alta escolaridade e renda, o dilema fica praticamente resolvido quando as atividades domésticas são delegadas para alguém. Por outro lado, para as mulheres, a delegação das atividades domésticas para outra mulher resulta em um aumento no tempo dedicado aos cuidados com filhos pequenos. Por fim, os resultados encontrados sugerem que quem tem empregada doméstica, em geral, pode usar um pouco mais do tempo livre para lazer.

Depois de ler os artigos que constituem o livro organizado por Clara Araújo e seus colegas, é inevitável não se perguntar: o que mudou e o que permanece como antes? Em um primeiro momento, tudo parece estar exatamente como antes. No entanto, é preciso ter em mente que somente o trabalho de Araújo, Picanço, Cano e Veiga compara as informações disponíveis para 2003 e 2016-2017. Os demais artigos analisam somente os resultados de 2016-2017. Esse fato não diminui a relevância dos artigos reunidos no livro. Na verdade, 
isso evidencia a necessidade de se continuar pensando e repensando as conexões existentes ente gênero, família e trabalho e abrir espaços para reflexões a respeito de relações de poder, contextos de opressão, anulação, submissão e insatisfação - particularmente (mas não exclusivamente) da mulher - que marcam, ainda hoje, os espaços públicos e privados onde as interações entre os indivíduos acontecem.

Os diferentes artigos revelam que a face conservadora das relações que se estabelecem ente homens e mulheres, no âmbito privado do domicílio - e que se difundem para outras esferas da vida -, ainda é bastante visível quando se olha a divisão de tarefas domésticas, tais como, lavar, passar e cuidar de filhos pequenos. Isso acontece independentemente da existência de percepções mais modernas que, como mostrado em alguns dos estudos, valorizam o compartilhamento de atividades entre o casal. Muitos resultados evidenciam que a participação masculina, tanto em tarefas domésticas como em atividades de cuidado com os filhos, vem crescendo. Embora isso seja positivo, vale pontuar que o aumento desse envolvimento ainda não foi suficiente para permitir que as mulheres deixem de concentrar a maior parte das atividades domésticas e não se sintam sobrecarregadas. Ainda estamos longe da equidade de gênero no que tange à conciliação entre família e trabalho.

Ademais, os artigos reunidos no livro motivam o leitor a pensar sobre quais condições são mais favoráveis e quais se configuram como obstáculos para a construção de relações de gênero mais igualitárias em uma sociedade que ainda possui tantos resquícios do patriarcalismo. Eles apontam para a relevância de se ponderar sobre o peso que a família possui na definição de papéis sociais e na edificação de relações de gênero menos ou mais igualitárias, pois é nesse microcosmo que se constroem as normas que definem o que se espera de homens e de mulheres. É também nele que se estabelecem as primeiras noções acerca do que é adequado para homens e mulheres, tanto no espaço público quanto no privado, onde tais expectativas e valores se consolidam e são passados adiante, de uma geração para outra, influenciando percepções e práticas futuras. Assim, como diria Prado (1981), se, por um lado, a família pode funcionar como um espaço de apoio e solidariedade, por outro, ela pode servir como um núcleo de imposição normativa, de coação e de conflitos.

A leitura dos artigos leva, portanto, a reflexões acerca da família, do mercado de trabalho e das relações de gênero e, embora os autores tenham considerado diferentes variáveis em suas discussões, os trabalhos não esgotam as questões envolvidas nas conexões que existem, não somente entre essas três dimensões, mas também entre elas e os diversos aspectos incluídos nas análises. Há, ainda, muito trabalho a ser feito e muito a ser compreendido. Afinal, do ponto de vista das relações de gênero, o real ainda está muito distante do ideal. 


\section{Referências}

HASENBALG, C. Discriminação e desigualdades raciais no Brasil. 2. ed. Belo Horizonte: Editora UFMG; Rio de Janeiro: IUPERJ, 2005.

ITABORAÍ, N. R. Mudanças nas famílias brasileiras (1976 - 2012): uma perspectiva de classe e gênero. Rio de Janeiro: Garamond, 2017.

PRADO, D. 0 que é família. São Paulo: Abril Cultural; Brasiliense, 1981.

\section{Sobre a autora}

Andréa Branco Simão é assistente social, doutora em Demografia pelo Centro de Desenvolvimento e Planejamento Regional (Cedeplar) da Universidade Federal de Minas Gerais (UFMG) e mestre em Sociologia pela Texas A\&M University. Professora do curso de Serviço Social da Pontifícia Universidade Católica de Minas Gerais e pesquisadora no Cedeplar.

\section{Endereço para correspondência}

Rua José Quirino Rosa, casa 222, Cond. Residencial das Braúnas 31-365590 - Belo Horizonte-MG, Brasil

Recebido para publicação em 28/08/2019 Aceito para publicação em 30/08/2019 